\title{
A arquitetônica do gênero musical sertanejo: cotejando enunciados presentes no livro Bem Sertanejo
}

\author{
Maria Sueli Ribeiro da Silva \\ Centro Universitário de Rio Preto (UNIRP), São José do Rio Preto, São Paulo, Brasil \\ mssuribeiro@yahoo.com.br \\ https://orcid.org/0000-0002-0012-9547
}

DOI: http://dx.doi.org/10.21165/el.v47i2.2021

\section{Resumo}

Com base no cotejo de enunciados do livro Bem Sertanejo, esta pesquisa pretende mostrar a construção da arquitetônica do gênero sertanejo, por meio do cotejo de enunciados presentes nos capítulos dessa obra, de modo a refletir de que forma gêneros musicais do sertanejo, como a música raiz, o sertanejo e o sertanejo universitário - fazem ressoar a cultura sertaneja e como vêm se relacionando com as mídias para propagação desse gênero.

Palavras-chave: gêneros musicais sertanejos; arquitetônica; cotejamento; Bem Sertanejo.

The architectural of the musical genre sertanejo: comparing statements present in the book Bem Sertanejo

\begin{abstract}
Based on the comparison of statements of the book Bem Sertanejo, this research intends to show the construction of the architectural genre of the sertanejo genre, by means of the comparison of statements present in the chapters of this work, in order to reflect in what form musical genres root music, sertanejo and universtity sertanejo make resonate the sertaneja culture and how it has been related to the media for the propagation of this genre.
\end{abstract}

Keywords: musical genre sertanejo; architectural; comparing; Bem Sertanejo.

\section{Introdução}

A diversidade cultural no Brasil é aceita, mas nem sempre é compreendida. As diversidades de hábitos, costumes regionais são exemplos de chacotas por parte ainda de muitos brasileiros. Vale a minha identidade cultural, sou um paulista. Mas não vale a identidade cultural do Nordestino, que é um repentista. Ser diferente na cor, no gênero, na linguagem ainda é um problema em nosso país. Se você fala o dialeto caipira, há um tipo de preconceito: o preconceito linguístico. Se você ignora um negro, há outro preconceito: o racial. É preciso quebrar a barreira do preconceito. A música é um dos meios que possibilitam entender que é aceitável toda diferença, toda diversidade.

Do preconceito social, nascem os estereótipos, como ocorreu com o caipira, apresentado por alguns como o ignorante, o matuto, o bicho do mato. Esse estereótipo provém de um discurso enunciado em um contexto social específico, construindo uma arquitetônica em que o sujeito é posto à margem, é marginalizado. 
Para Bakhtin (2006), o signo linguístico deve ser estudado além de sua realidade literal, por ser a palavra reveladora das relações sociais e de suas significações, tanto quanto seus contextos de uso. Se os discursos são enunciados e os enunciados palavras para além do signo, nesse sentido "ser caipira" está para além do preconceito, do estereótipo. O caipira, o matuto, o homem do campo, o sertanejo é léxico de arquitetônicas construídas na relação desse sujeito com outrem.

A linguagem é histórica, é social, é também a vida. Esta se faz na arte, na ótica bakhtiniana, por exemplo, a letra de uma música raiz ou sertaneja. É no contexto histórico, social, de vida e de arte que o dialeto caipira compõe também a língua portuguesa do Brasil. Há uma relação dialética, uma está na outra. Só assim designam sentidos, frases e discursos. Os discursos são feitos de enunciados que envolvem "eu" e "outro".

O presente estudo tratou da arquitetônica da cultura sertaneja, a partir de gêneros musicais relacionados a esse gênero, que são: a música raiz, a música sertaneja e a música sertaneja universitária. Com base nos estudos bakhtinianos e de conceitos desenvolvidos pelos intelectuais do Círculo, levamos à discussão e à compreensão de gestos de leitura e de enunciados presentes nestes gêneros musicais.

De modo específico, buscou-se compreender a relação das vozes presentes nesses gêneros, a partir de enunciados dos cantores apresentados no livro Bem Sertanejo, de autoria do cantor Michel Teló e do jornalista André Piunti, no qual é mostrada a história da música sertaneja no país, em relação às mídias de cada época (como rádio e TV).

\section{Procedimentos metodológicos}

Para este artigo, realizou-se uma pesquisa qualitativa, voltada à filosofia da linguagem, com base nos estudos de Bakhtin e estudiosos do Círculo. A constituição do corpus de análise foi feita com base em uma pesquisa exploratória e documental, a partir do projeto Bem Sertanejo, o qual engloba, primeiramente, o Programa Bem Sertanejo do Fantástico, da emissora Rede Globo, o livro Bem Sertanejo e o site Bem Sertanejo. Porém, para este trabalho, tomou-se somente a análise de enunciados presentes no livro desse projeto, o qual mostra vozes sociais e dos cantores de cada gênero musical do sertanejo.

Em seu livro, Estética da Criação Verbal (2011), Bakhtin traz, em um dos capítulos, uma metodologia de análise de enunciados de textos, que denomina de cotejamento ou ainda de correlacionamento, mostrando que a índole dialógica dos textos se baseia no cotejo, ou seja, no correlacionamento, como se nota a seguir:

A interpretação como correlacionamento com outros textos e reapreciação em um novo contexto (no meu, no atual, no futuro). [...] Etapas do movimento dialógico da interpretação: o ponto de partida - um dado texto, o movimento retrospectivo contextos do passado, movimento prospectivo - antecipação (e início) do futuro contexto (BAKHTIN, 2011, p. 401).

Assim, para este estudo, fez-se a análise de enunciados presentes, buscando compreender a relação entre os gêneros musicais do sertanejo (raiz, sertanejo e sertanejo universitário) por meio das vozes sertanejas que são contempladas na obra. 
Como esse estudo se volta à ótica da filosofia da linguagem, e não da teoria da análise do discurso, tomou-se por base a noção de "cotejo" (ou "correlacionamento") apresentada por Bakhtin.

Na visão bakhtiniana, o cotejo é, por assim dizer, uma orientação metodológica que se origina da valoração do outro, da relação de alteridade, passando a se caracterizar como reflexo, refração e construto da produção de conhecimentos pelos seres humanos e não uma mera reprodução sem refratar a realidade circundante, ou seja, sem deixar de se remeter à história, à ideologia, às práticas sociais, à heterogeneidade (SILVA, 2017).

Para Fiorin (2012, p. 151), “[...] captar as relações do texto com a história é apreender esse movimento dialético da constituição do sentido". Dessa forma, por meio do cotejo de enunciados de cantores do sertanejo, esse estudo buscou verificar sentidos contidos nos gêneros musicais sobre a cultura sertaneja.

\section{Concepção de cultura e de gênero na visão bakthiniana}

De acordo com Bakhtin (2006), a cultura é composta de discursos que retêm a memória coletiva em relação ao que cada sujeito é obrigado a se situar. $O$ termo "discurso" pode, então, ser definido como aquilo que pretende significar algo a outro, com a intenção de lhe transmitir um conjunto de informações coerentes, e essa coerência é uma condição essencial para que o discurso seja entendido. São as mesmas regras gramaticais utilizadas para dar uma estrutura compreensível ao discurso que simultaneamente funcionam com regras lógicas para estruturar o pensamento.

$\mathrm{Na}$ Era da Informação, a sociedade passa a ser mais tecnológica; além da comunicação de massa (TV, rádio), os indivíduos utilizam a comunicação virtual, a internet. E, por meio dela, acessam informações, buscam conhecimento, interagem com seus interlocutores por meio de redes sociais, selecionam programas, reportagens, vídeos, músicas, de acordo com sua preferência.

Esses avanços tecnológicos vêm favorecendo as diversas produções midiáticas, como a construção de videoclipes e de programas de TV, que atraem a população, sobretudo os jovens. Nessas produções estão disponibilizadas várias informações e discursos que influenciam direta ou indiretamente a vida e a cultura de um povo. Recentemente, programas de TV, por exemplo, estão se voltando à cultura raiz ou à cultura sertaneja, buscando levar o verdadeiro valor dessa cultura e desfazer preconceitos. Cada veículo de comunicação, como a TV e a internet, enfatiza essa cultura de uma forma e com um determinado discurso. Cada discurso se orienta por uma determinada argumentação, ou ainda se centra, principalmente, na persuasão.

Os discursos desempenham diversas funções, assumem várias modalidades e utilizam diferentes estilos de linguagens e gêneros discursivos. Segundo Bakhtin (2011, p. 262), "a riqueza e a diversidade dos gêneros do discurso são infinitas porque são inesgotáveis as possibilidades da multiforme atividade humana [...]". E cada campo de atividade apresenta um repertório integral de gêneros do discurso, "que cresce e se diferencia à medida que se desenvolve e se complexifica um determinado campo".

No que tange à música sertaneja, pode-se dizer que é "o repetível e o novo se dando juntos"; os gêneros (raiz, sertanejo e sertanejo universitário) se relacionam, a tradição se repete e se renova no tempo e no espaço, se junta e se separa, isto é, 
dialogam, vão além do discurso verbal, formando uma arquitetônica com sentidos dentro e fora desta (PAJEÚ, 2014).

Muitos significados envolvem o termo "sertanejo", ou seja, muitas relações se fazem com essa palavra. São relações que, muitas vezes, constroem um discurso de preconceito, de divisão, de discriminação, de massificação, de mercado; e, outras vezes, um discurso de agregação, de paixão, de tradição e cultura, de não acabamento, de estarse e por fazer, de pertencimento social, de empoderamento cultural, que só podem ser notados no aqui e agora, ou seja, na constituição dos gêneros musicais, também chamados de "sertanejo".

\section{O gênero musical sertanejo}

Sobre a constituição dos gêneros da música sertaneja, Oliveira (2009) mostra que, antes da década de 30, a expressão "música sertaneja" denotava, indistintamente, toda música decorrente do interior do Brasil, por exemplo, o cateretê no interior paulista e o baião no interior nordestino. Nas décadas de 30 e 40, há a separação dos universos musicais do Nordeste e do Centro-sul, sendo chamada de "música caipira" a música do interior Centro-sul. Já a partir dos anos 60, a expressão "música sertaneja" passa a denotar a "música caipira" no espaço social urbano, tendo influências de outros estilos. A nova terminologia já retrata a constituição de um novo gênero discursivo sertanejo.

Assim, passou-se a utilizar a terminologia "música raiz", "música caipira" ou "moda de viola" às canções que remetem à cultura, ao estilo e ao modo de vida no campo. E o termo "música sertaneja" passou a retratar a música que não tem mais como instrumento principal a viola, não tem somente a temática do campo, mas que sai também do interior do Brasil e, por essa razão, é "música sertaneja".

Com a internet e a globalização, o gênero sertanejo acaba fazendo incorporações tecnológicas e de ferramentas de propagação. Do velho radinho de pilha, hoje se houve o sertanejo pelos celulares. E outro gênero da música sertaneja passa a ser construído: o sertanejo universitário. O termo "universitário" mostra sua propagação não só no espaço urbano, mas, sobretudo, entre os jovens que, em sua grande maioria, são universitários. No gênero musical sertanejo universitário, há uma referenciação da cultura do interior do país, como o estilo de se vestir (bota, chapéu), há influências de canções e de cantores de música raiz ou da música sertaneja, dos anos 60 a 90, mas não há mais primazia da viola caipira, não há só duplas. Há linguagem e os espaços, contemplados nas letras, são dos jovens de hoje, os ritmos se misturam, sendo construídos com o funk, o tecnobrega, entre outros gêneros musicais.

A concepção de linguagem, na visão bakhtiniana, considera a interação verbal, social e ideológica, que mostra os conflitos e as contribuições para constituir o sujeito dialógico. A interação dialógica dos discursos se faz não só no âmbito ideológico, mas também no âmbito social.

Com isso, as características ideológicas do sertanejo ressalvam o seu valor histórico e contribuem para o entendimento de sua constituição final, pois entender os gêneros musicais sertanejos é também dialogar com o passado e todas as suas fases até chegar aos dias atuais. 


\section{O Projeto Bem Sertanejo}

De acordo com Teló e Piunti (2015), o projeto Bem Sertanejo foi pensado, inicialmente, em 2011, pelo cantor sertanejo Michel Teló e seu irmão mais velho e também empresário dele, Teófilo. O projeto seria, primeiramente, um DVD musical, em que todas as fases da música sertaneja pudessem ser retratadas e ainda fosse contada a história do gênero sertanejo por meio das canções.

Em razão de sucesso e do número de shows que Michel Teló fez entre 2011 e 2013, o projeto ficou parado e, no final de 2013, Teló resgatou novamente o projeto, vindo a apresentá-lo ao produtor musical do programa Fantástico, da Rede Globo, que, após aprovação dos diretores da emissora, acatou a ideia do cantor sertanejo.

No livro Bem Sertanejo, que é parte desse projeto de Teló e seu irmão, é possível observar o detalhamento de cada passo do projeto e as reais motivações do cantor ao trazer um discurso apaixonado por sua origem. Desse modo, verificou-se que a proposta do projeto é contar a história da música sertaneja, na voz dos artistas desse gênero e das principais canções que marcaram cada um dos gêneros musicais (raiz, sertanejo e sertanejo universitário).

O gênero sertanejo é resgatado nesse projeto, por Teló, por meio de uma visão sócio-histórica, marcada por vozes diversas que representam cada gênero musical que compõem o sertanejo. Ele busca, por meio do cotejamento dos diversos gêneros musicais (raiz, sertanejo e sertanejo universitário), mostrar a história do gênero sertanejo e suas relações com os meios de comunicação, trazendo um pouco da história do rádio, um pouco da televisão e seus bastidores, expandindo essa narrativa também na internet.

Ainda nesse projeto, Teló toma a posição de apresentador e de entrevistador, buscando sempre um diálogo informal, descontraído, mas singular com cada representante da música sertaneja. Além disso, para contar um pouco da história do sertanejo no país, Teló fez entrevistas com representantes de cada gênero da música sertaneja. Para tratar da história da moda de viola, ele entrevistou, por exemplo, o cantor Almir Sater; para abordar a música sertaneja, Teló dialogou com a dupla Chitãozinho e Xororó, entre outros; ele trouxe várias vozes também do sertanejo universitário, mas, para esse estudo, o próprio Teló será a voz representante desse gênero.

Bakhtin (2011) concebe os enunciados no tempo e no espaço, de modo a dialogar e ampliar seu sentido. Assim, por exemplo, o sertanejo, por longos anos, ganhou os lares dos brasileiros com a música caipira ou música raiz, o qual contou histórias e criou conceitos.

Durante o período da Era do Rádio (1940-50), as pessoas paravam em frente ao veículo radiofônico para se emocionar com as radionovelas e se divertir com os humorísticos, além de se informar sobre a Segunda Guerra Mundial; nesse período, o sertanejo também encontrou no rádio o alavanque para sua divulgação.

De cultura caipira passa a cultura sertaneja, em que o espaço na música sertaneja é ampliado e seus enunciados não se dão somente no campo, na roça, mas tratam também do deslocamento e conflitos emocionais em outros espaços, em especial, no contexto urbano. 
As mídias (rádio e TV) fizeram mais parte da história e do advento da música raiz e da música sertaneja; enquanto as transmídias (plataformas da internet que relacionam sites, Facebook, YouTube, entre outros) fazem parte da história do sertanejo universitário. No caso do projeto Bem Sertanejo, o recurso tecnológico vem sendo utilizado com êxito, no intuito de levar a história da música sertaneja tanto para o público fiel ao gênero como a outros que não o conhecem, através da internet.

\section{O cotejo: compreendendo os enunciados}

Como visto, o Projeto Bem Sertanejo foi elaborado por Michel Teló e seu irmão Teófilo em 2011. Saiu do papel em 2014, quando, inicialmente, se concretizou como quadro do Fantástico. O livro Bem Sertanejo: a história da música que conquistou o Brasil tem autoria de Michel Teló e do jornalista André Piunti e foi publicado em 2015. A história do gênero é contada por meio de várias vozes que compõem o sertanejo.

A narrativa desse livro faz ainda relação com os meios de comunicação, trazendo um pouco da história do rádio, da televisão e expansão do gênero com a internet, por meio das redes sociais e de sites. O livro compõe-se ainda de 12 capítulos, além da introdução que conta a vida de Teló. Cada capítulo destina-se a duas vozes do sertanejo. No capítulo 1, por exemplo, as vozes presentes são do cantor Chitãozinho e de seu irmão e parceiro de dupla Xororó, além das vozes de Teló e do jornalista André Piunti.

Os enunciados presentes no livro retratam as vozes dos cantores sertanejos, a voz de Michel Teló como narrador protagonista e a voz do jornalista André Piunti, ao trazer informações e notas que complementam a história do sertanejo e dos próprios entrevistados. Com isso, ao se analisar esses enunciados, pretende-se interpretar discursivamente o que enunciam essas vozes, tal como aborda Souza-e-Silva (2012, p. 193): "Não se trata aqui de analisar um ou mais textos apenas 'textualmente', ou seja, em termos de mecanismos de coesão, referenciação, etc., mas de interpretá-los discursivamente como manifestações específicas historicamente autorizadas".

Para este artigo, tomou-se para o cotejo de enunciados a história da dupla Chitãozinho \& Xororó, retratada no capítulo 1 do livro, bem como a história do cantor Almir Sater, mostrada no capítulo 4 do livro. A escolha por essas histórias foi baseada na importância estética e ética que esses cantores têm junto a outros artistas sertanejos. A dupla Chitãozinho \& Xororó é uma dupla pioneira em levar a música sertaneja às FMs e à TV, apresentam carreira de longa data, com mais de 40 anos. Já o cantor Almir Sater apresenta um percurso histórico, no mínimo, curioso, já que saiu do estilo roqueiro para o estilo sertanejo, sendo um importante instrumentista da música raiz e reconhecido internacionalmente.

Para dialogar com os artistas do sertanejo, Teló utilizou o gênero entrevista, reproduzindo as perguntas e as respostas de cada cantor, levando o leitor a participar de um momento único, singular, particular da história desses artistas. Em cada entrevista, foi escolhido um ambiente para filmagem e fotografia e tais ambientes remetem à vida, ao cotidiano familiar de cada cantor. No capítulo 1, por exemplo, a entrevista ocorreu na casa do cantor Chitãozinho, na cidade de Campinas, interior paulista. No capítulo 4, a entrevista com Almir Sater foi em uma de suas fazendas no Mato Grosso do Sul. 
No capítulo 1, notou-se ainda que, em alguns momentos, foi usado o discurso indireto, quando Teló traz uma breve história sobre a dupla; nessa narrativa, Teló constrói seu discurso em primeira pessoa, como se observa nos enunciados (1) e (2):

Voz do cantor Michel Teló:

[...] com sete, oito anos de idade, cantei "Fogão de lenha", hit deles. (p. 25)

Voz do cantor Michel Teló:

[...] eu fazia sucesso em Campo Grande como o menino que cantava "Galopeira", porque copiava o jeito deles de cantar. (p. 25)

Teló relaciona sua história de cantor à história da dupla, mostrando como essa o influenciou e ainda influencia muitas gerações de cantores de música sertaneja. Foi "copiando" o jeito de eles cantarem que Teló foi tomando gosto pela música sertaneja.

O cantor Michel Teló considera-se um cantor da geração dos sertanejos universitários, mas, em seu livro, busca mostrar a todo instante, seja na sua narrativa ou na voz dos próprios artistas entrevistados, como há reverberações dos cantores pioneiros do sertanejo, como é o caso de Chitãozinho \& Xororó, cujo estilo musical ressoou na voz de Teló, como se verifica no enunciado: “[...] cantei 'Fogão de Lenha', hit deles”.

Em outros momentos do capítulo, utilizando o discurso indireto, o jornalista André Piunti traz informações adicionais sobre a dupla, como no enunciado (3):

Voz do jornalista André Piunti:

A história de Chitãozinho \& Xororó serviria de pano de fundo para explicar como, através deles mesmos, a década de 1980 mudou o rumo da música sertaneja. (p.27)

Nesse enunciado, Piunti mostra como essa dupla viria a influenciar a música sertaneja, nos anos 80, e como o pioneirismo e a inovação que trouxeram, seja pelo rádio seja pela $\mathrm{TV}$, marcaram (e ainda marcam) a história do sertanejo no Brasil, ao dizer: "[...] a história de Chitãozinho \& Xororó [...] mudou o rumo da música sertaneja".

Há, nesse momento, a reverberação da história da dupla no sertanejo, cujo ato responsável dessa dupla, ao serem os primeiros a levar o sertanejo para rádios FMs e ao ser a primeira dupla a se apresentar num programa de TV e a receber um prêmio, confrontando com os valores e os estilos musicais da época (samba e bossa nova), fez com que a música sertaneja hoje fosse projetada em nível nacional e se tornasse uma manifestação cultural e artística aceita. Pois, até então, os artistas interioranos do país, sobretudo do sertanejo, eram marginalizados pelos meios de comunicação, priorizandose apenas os estilos musicais tocados e cantados nas principais capitais brasileiras, como o Rio de Janeiro.

E, usando o discurso direto, em que aparece a voz da dupla, num bate-papo com Teló, é que aparece a ética (o cotidiano) desses cantores no início da carreira, quando o sertanejo não era visto como gênero musical, mas como uma música apreciada por uma minoria que só ouvia o rádio, como se nota em (4) e (5): 
As pessoas descobriram o disco e começaram a pedir nas rádios. [...] Ficamos dois anos sem gravar, curtindo o sucesso. Foi a música que abriu as portas. Depois vieram outras e outros artistas fazendo trabalhos bons. Todo mundo ajudou nessa abertura. (Disco "Somos Apaixonados"; Música: "Fio de Cabelo") (p. 28)

(5) Voz do cantor Xororó:

Depois do sucesso de "Fio de Cabelo", começamos a prestar atenção na plateia. Era um público muito jovem, os estudantes, mulherada [...]. Mas na hora do show, chegava o Chitão, eu, um irmão tocando baixo e um sanfoneiro. Era tudo meio devagar [...]. (p. 28)

No enunciado (4), que ecoa a voz de Chitãozinho, nota-se que a relação com o público-alvo desse gênero se iniciou pelo rádio: "As pessoas [...] começaram a pedir nas rádios [...]". Além disso, mesmo com o hit de sucesso "Fio de Cabelo", a conquista do espaço e do reconhecimento desse gênero por outros meios de comunicação e outro público foi, sem dúvida, muito lenta, como mostrado em: "Era tudo meio devagar [...]".

É interessante observar que essa dupla vem em destaque, sendo colocada já no primeiro capítulo. Isso porque são pioneiros em várias mudanças ocorridas na história da música sertaneja no país. Como se observa no enunciado (4), nesse momento histórico da vida da dupla, o impulsionador de suas canções foi o rádio.

Nesse diálogo, entre Teló e a dupla, Xororó traz o que os levou a se tornarem um ícone da música sertaneja, e não da música raiz: o olhar para o público. Olhando e se pondo à escuta do seu público, a dupla viu que o público mudara: "Era um público muito jovem, os estudantes, mulherada [...]". Assim, era preciso mudar, era preciso algo novo, porque "[...] era tudo meio devagar $[\ldots]$ ", como enunciado em (5).

Conforme Bakhtin (2011, p. 275), "Os limites de cada enunciado [...] são definidos pela alternância dos sujeitos do discurso, ou seja, pela alternância dos falantes. [...] O falante termina o seu enunciado para passar a palavra ao outro ou dar lugar à sua compreensão ativamente responsiva”.

Na alternância de fala da dupla, nota-se a compreensão responsiva de cada um em relação ao momento histórico que viveram e que os fez repensar o estilo da música sertaneja. Nesse sentido, a relação com o outro, que nesse caso foi o público da época, levou à mudança da arquitetônica desse gênero, transformando o visual, a tecnologia e a instrumentalidade do gênero sertanejo, não mais usando apenas a viola e a sanfona.

Teló, em seu livro, tem como pergunta central, a cada artista: Quem o inspirou a cantar e a ser um cantor sertanejo? E o próprio Teló, ao final do livro, ressalta a influência de nomes mais cotados entre os artistas, como Tonico \& Tinoco, Tião Carreiro \& Pardinho, bem como a própria dupla Chitãozinho \& Xororó, como enuncia em (6).

Voz de Michel Teló:

Usaríamos as respostas para apresentar ao público duplas que não tiveram tanta mídia, mas que foram importantes. Com o passar dos episódios, três nomes foram repetidos à exaustão: Tonico \& Tinoco, Tião Carreiro \& Pardinho e Chitãozinho \& Xororó. (p. 36) 
Já Xororó relaciona sua preferência musical a vozes do rádio da época em que iniciaram sua carreira, como a dupla sertaneja Jacó \& Jacozinho, a qual tinha um timbre de voz semelhante ao da voz deles, como enunciado em (7).

Voz do cantor Xororó:

[...] Ouvíamos a Rádio Nacional que tocava sertanejo do final da tarde até as dez da noite. Como não tínhamos rádio em casa, ouvíamos na serraria. Tinha Tião Carreiro \& Pardinho, Tonico \& Tinoco, Liu \& Léu. Mas a dupla que mais gostávamos era Jacó \& Jacozinho por causa do timbre da voz. Eles cantavam todas as sextas-feiras à noite. (p. 36)

Nesse sentido, Bakthin (2011, p. 28) argumenta que "é preciso reconstruir radicalmente toda arquitetônica do mundo do sonho, introduzindo-lhe um elemento absolutamente novo [...]" e mostra que a arquitetônica é reconstruída pela "[...] possibilidade de afirmação volitivo-emocional da minha imagem a partir do outro e para o outro $[\ldots]$ ".

Percebe-se, nos enunciados (6) e (7), que cantores como a dupla Chitãozinho \& Xororó são, por assim dizer, cantores sertanejos em relação ao que outros artistas já fizeram anteriormente, como a dupla de música raiz Tião Carreiro \& Pardinho. Esses cantores do gênero raiz ainda ecoam nas vozes dos novos artistas sertanejos e da nova geração de sertanejos, da qual faz parte o próprio Teló.

A arquitetônica do gênero sertanejo está sendo construída por essa relação entre as vozes e os gêneros sertanejos, que a partir da imagem do outro (nesse caso, dos cantores de música raiz que inspiraram as demais gerações) e para o outro (cantores da música sertaneja e do sertanejo universitário) contribuem à criação do gênero sertanejo. A ética de Xororó foi baseada na estética da dupla sertaneja Jacó \& Jacozinho; por sua vez, a ética da nova geração de sertanejos, como a de Michel Teló, tem relação com a estética de Chitãozinho \& Xororó.

O pioneirismo da dupla Chitãozinho e Xororó, dentro do contexto sertanejo, vai se alargando, pois não apenas ela fez a inovação instrumental e a propagação do gênero em rádio FM. No enunciado (8), Piunti mostra como essa dupla levou a música sertaneja a ser trilha sonora de uma grande novela da TV Globo, emplacando sucessos e abrindo portas a outro tipo de trabalho para os artistas sertanejos.

Voz do jornalista André Piunti:

Em 1989, pela primeira vez, uma dupla sertaneja emplacou em uma trilha de novela das oito. A canção se chamava "No rancho fundo", originalmente um samba, que havia sido gravado por Chitãozinho \& Xororó. (p. 38)

Também na entrevista com a dupla, o cantor Chitãozinho revela que a música Rancho Fundo foi o primeiro sucesso da dupla em tema de novela, como enunciado em (9); porém, tal canção pertence ao gênero samba, pois esta foi escrita pelos saudosos sambistas Ary Barroso e Lamartine Babo. Mas ainda hoje, muitos pensam que essa música é de autoria da dupla, devido ao sucesso que ela repercutiu na voz desses cantores sertanejos. 
(9) Voz do cantor Chitãozinho:

[...] Essa música é do Ary Barroso e do Lamartine Babo. Eles fizeram um projeto em homenagem ao Ary Barroso e nos pediram para cantar. [...] Foi nosso primeiro tema de novela, que coisa linda que foi aquilo. (p. 38)

Observa-se, em (9), que o samba de Ary Barroso e Lamartine Babo se tornou singular na voz da dupla, trazendo uma nova relação com o público e um marco na carreira dos artistas. Apesar de ser inicialmente a letra de um samba, a canção Rancho Fundo se alargou ao encontrar-se com o gênero sertanejo, provocando no outro uma nova inter-relação da arte e da vida. Como diz Bakhtin (2011, p. XXXIV), "arte e vida são a mesma coisa, mas devem tornar-se algo singular em mim, na unidade da minha responsabilidade".

Também num modo singular e próprio de ver o sertanejo, que Almir Sater tomou contato com esse gênero, como revela o cantor no livro de Teló. A entrevista com esse cantor de moda de viola foi na sua fazenda em Aquidauana, no Mato Grosso do Sul, numa região pantaneira. No livro, o cantor representa a tradição da música raiz através da viola caipira, instrumento este que consagrou a carreira de Almir.

O jornalista André Piunti revela que a formação musical é diferente dos demais cantores sertanejos, como se nota no enunciado (10); na sequência, Almir fala da sua relação com o pop rock e seu encontro com a viola caipira, por meio do pontilhado de Tião Carreiro, como enunciado em (11) e (12).

(10) Voz do jornalista André Piunti:

A formação musical de Almir é diferente de grande parte dos sertanejos. Violeiro respeitado e premiado, o jovem roqueiro saiu de Campo Grande para estudar Direito. Pelo menos, é o que seu pai achava. (p. 96)

(11) Voz do cantor Almir Sater:

Fui pro Rio de Janeiro fazer faculdade. [...] A faculdade só servia pra eu sair com a moçada e tocar. Na época, [...] Simões estava morando no Rio. Inventei umas três aulas com ele. "Simões, eu estou precisando de uma aula de Bob Dylan”. [...] Ficamos parceiros a partir daí. (p. 96)

(12) Voz do cantor Almir Sater:

Eu venho de uma geração que curtia Pink Floyd. [...] e ao mesmo tempo eu gostava de Tião Carreiro \& Pardinho, Liu \& Leú, [...] etc. [...] Nessa época, tínhamos a música folclórica dos Andes, a música irlandesa, que deu origem à música country americana, que nos influenciou e que influenciou também o rock'n'roll por meio do blues. Tive a chance de ouvir essa miscelânea toda $[\ldots] .(p .97)$

Como a dupla sertaneja Chitãozinho e Xororó, o cantor de música raiz Almir Sater é um dos poucos sertanejos que teve um percurso artístico impulsionado pela televisão. Diferente da dupla que cantava e fazia trilhas sonoras de novelas, Almir Sater atuou como protagonista de várias novelas, e estas ajudaram a impulsionar sua carreira, passando a ser reconhecido nacionalmente como cantor de moda de viola, como se nota no enunciado (13), na voz do jornalista Piunti: 
Almir faz parte de um pequeno time de sertanejos que foram destaques em novelas. Em sua história, as novelas tiveram papel mais importante [...], por meio delas que ele se tornou nacionalmente conhecido [...]. (p. 99)

É também de autoria de Almir Sater a música Luzeiro, trilha sonora da abertura do Programa Globo Rural, como se observa no enunciado (14).

(14) Voz do Jornalista André Piunti:

Apesar de as novelas serem sua principal relação com a televisão, desde 1986, Almir entra, por causa de sua música, na casa de milhares de brasileiros. É de sua autoria a trilha de abertura do programa Globo Rural, a canção instrumental "Luzeiro". (p. 104-105)

Essa canção instrumental faz ressoar através da televisão a típica moda de viola caipira ou música raiz e, para Almir, tem uma relação direta com tudo que há em sua vida, inclusive a educação e a criação dada aos filhos, ditas no enunciado (15). É uma relação de amorosidade e de gratidão a esse estilo musical, que o fez deixar de ser roqueiro para se tornar um típico sertanejo.

(15) Voz de Almir Sater:

Essa música praticamente criou os meus filhos, devo muito a ela. Materialmente me ajudou muito. (p. 105)

Desse modo, notou-se que o cantor assume seu ato responsivo perante a música sertaneja, mostrando a relação com o outro, no seu encontro com o repicar da viola de Tião Carreiro, mas não deixando de lado o amor pelo instrumental, como Teló e Piunti (2015) enunciam em seu livro. Essas vozes e estilos totalmente diferentes compõem a arquitetônica da ética e estética do cantor sertanejo Almir Sater, que, ao som da viola, fez ressoar o estilo sertanejo raiz, sobretudo por meio da mídia televisiva.

\section{Considerações finais}

As vozes e cotejos de vozes presentes na obra de Teló não se esgotam aqui. A riqueza de detalhes e de histórias típicas é imensa e compõem a narrativa do livro. No entanto, nesse estudo, o intuito foi mostrar uma parte desses cotejos de vozes, a fim de analisar como a arquitetônica do sertanejo vem se constituindo.

Assim, verificou-se que, no diálogo (nas conversas) que a obra propõe, esses artistas entrevistados fazem ecoar as vozes, muitas vezes, silenciadas pelas mídias (rádio e TV), como Jacó e Jacozinho, Liu e Léu, entre outros, bem como traz vozes da música raiz que ressoam nas vozes do sertanejo na atualidade, como na voz do próprio Michel Teló, que representa a nova geração de cantores sertanejos. Observou-se ainda que a relação com outros gêneros, como o samba e o rock, não é algo do sertanejo contemporâneo, denominado de "sertanejo universitário"; como visto na compreensão dos enunciados, a dupla Chitãozinho \& Xororó já trazia uma relação com outro gênero (que não o sertanejo), e o cantor Almir Sater de roqueiro passou a sertanejo, trazendo suas influências para o seu estilo de tocar viola. 
Nas entrevistas, notou-se que as histórias e as fases desse gênero têm um acabamento provisório até o encontro com outra realidade. Por meio da narratividade, da sua composição e dos seus enunciados, o livro vem mostrar que esse gênero conquistou o Brasil por ainda estar se fazendo. A arquitetônica do livro é mostrar que o gênero sertanejo se constituiu no encontro com os demais gêneros musicais, sobretudo no encontro com a moda de viola, com o sertanejo romântico, numa relação ética (vida) e estética (arte), como diz Teló: "a música sertaneja faz parte da vida, da cultura e do coração de cada brasileiro. E nós vamos levar isso pra frente".

\section{REFERÊNCIAS}

BAKHTIN, M. Estética da Criação Verbal. 6. ed. São Paulo: Martins Fontes, 2011. . Marxismo e filosofia da linguagem. 12. ed. São Paulo: Hucitec, 2006.

FIORIN, J. L. Da necessidade da distinção entre texto e discurso. In: BRAIT, B.; SOUZA-E-SILVA, M. C. (Orgs.). Texto ou discurso? São Paulo: Contexto, 2012. p. $147-165$.

OLIVEIRA, A. de P. Miguilim foi pra fora da cidade ser cantor: uma antropologia da música sertaneja. 2009. 325 f. Tese (Doutorado em Antropologia Social) - Centro de Filosofia e Ciências Humanas, Universidade Federal de Santa Catarina, Florianópolis, 2009.

PAJEÚ, H. M. Os gêneros do discurso na criação estética colaborativa. São Carlos: Pedro \& João Editores, 2014.

SILVA, M. S. R. da. O cotejo em torno do sagrado. In: GEGe - Grupo de Estudos dos Gêneros do Discurso. Palavras e contrapalavras: entendendo o cotejo como proposta metodológica. São Carlos: Pedro \& João Editores, 2017.

SOUZA-E-SILVA, M. C. Texto/Discurso: qual a relação com a leitura? In: BRAIT, B.; SOUZA-E-SILVA, M. C. (Orgs.). Texto ou discurso? São Paulo: Contexto, 2012. p. 183-193.

TELÓ, M.; PIUNTI, A. Bem Sertanejo. São Paulo: Editora Planeta do Brasil, 2015.

Recebido em: 26/09/2017

Aprovado em: 07/12/2017 